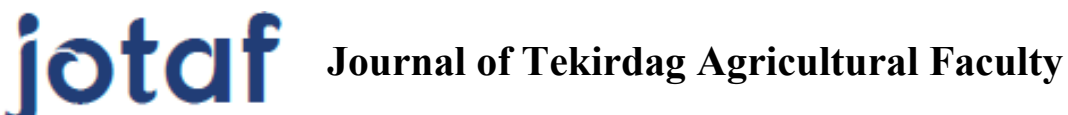 \\ Tekirdağ Ziraat Fakültesi Dergisi
}

\section{Kirece Bir Alternatif Olarak Şlam Uygulamasının Asit Reaksiyonlu Toprakta Biber (Capsicum annuum var. Cerasiforme) Bitkisinin Beslenmesine Etkileri}

\author{
The Effects of Vinasse Application as an Alternative to Lime on Nutrition of Pepper Plant \\ (Capsicum annuum var. Cerasiforme) in an Acidic Soil
}

\author{
Bülent YAĞMUR ${ }^{1 *}$, Bülent OKUR ${ }^{2}$, Nur OKUR ${ }^{3}$
}

\section{$\ddot{O} z$}

Bu çalışmada; farklı form, miktar ve kombinasyonlarda kireçleme materyalleri (granül ve toz) ile şeker fabrikası atığı şlam uygulamalarının asit reaksiyonlu bir toprağın $\mathrm{pH}$, mineral madde içeriği ile biber bitkisinin verim ve besin madde içeriği üzerine etkisi araştırılmıştır. Araştırma saksı denemesi şeklinde serada yürütülmüştür. Araştırma materyali toprağın pH'sını bir birim yükseltmek için ( $\mathrm{pH}$ 5.50'den $\mathrm{pH}$ 6.50'e) gerekli olan kireç ihtiyacı hesaplandıktan sonra deneme konuları oluşturulmuştur. Deneme konuları K (Kontrol), TK (Toz Kireç; \%90 $\mathrm{CaCO}_{3}, \% 5 \mathrm{MgCO}_{3}$ ), GK (Granül Kireç; \%90 CaO), ŞL (Şlam), 1/4 TK+3/4 ŞL, 1/2 TK+1/2 ŞL, 3/4 TK+1/4 ŞL, 1/4 $\mathrm{GK}+3 / 4$ ŞL, $1 / 2 \mathrm{GK}+1 / 2$ ŞL ve $3 / 4 \mathrm{GK}+1 / 4$ S S şeklinde saptanmıştır. Araştırmada toprak pH'sını bir birim yükseltmek için yapılan hesaplama sonucunda saksılara $300 \mathrm{~kg}$. da $\mathrm{da}^{-1}$ hesabı ile kireç uygulanmış ve saksılar bir ay süre ile inkübasyona bırakılmıştır. Saksılara biber fidesi dikiminden önce temel gübreleme (N, P, K) yapılmış̧ır. Araştırmadan elde edilen sonuçlara göre; toprak pH'sının yükselmesinde en fazla etkili uygulama toz kireç olmuş, granül kirecin ise şlam ile aynı etkiyi gösterdiği saptanmıştır. pH's1 5.50 olan kontrol toprağının pH'sı TK uygulaması ile $6.42^{\prime}$ ye, $1 / 2 \mathrm{TK}+1 / 2$ ŞL uygulaması ile de 6.41 'e kadar çıkarılması sağlanmıştır. Uygulamalar gerek toprağın makro ve mikro (toplam $\mathrm{N}$, faydalı $\mathrm{P}, \mathrm{Ca}, \mathrm{Fe}$ ve $\mathrm{Zn}$ ) gerekse bitkinin makro ve mikro besin element (toplam $\mathrm{N}, \mathrm{P}, \mathrm{Fe}, \mathrm{Cu}, \mathrm{Zn}$ ve $\mathrm{Mn}$ ) içeriklerini kontrole oranla önemli oranlarda artırmıştır. Biber verimini artıran ilk üç uygulama ise TK $>$ ŞL $>$ GK şeklinde bir sıralama göstermiştir. Araştırma sonucunda asit reaksiyonlu topraklarda kireç uygulamalarının yanı sıra, şlamın da alternatif bir kireç materyali olarak tarımsal alanlarda kullanılabilme potansiyeli bulunduğunu göstermiştir.

Anahtar Kelimeler: pH, Toz kireç, Granül kireç, Şlam, Biber, Toprak, Verim, Besin maddesi

\footnotetext{
1*Sorumlu Yazar/Corresponding Author: Bülent YAĞMUR, E.Ü. Ziraat Fakültesi Toprak Bilimi ve Bitki Besleme Bölümü, Bornova, İZMíR,. E-mail: bulent.yagmur@ege.edu.tr (D) OrcID: 0000-0002-7645-8574

Bülent OKUR, E.Ü. Ziraat Fakültesi Toprak Bilimi ve Bitki Besleme Bölümü, Bornova, İZMİR. E-mail: bulent.okur@ege.edu.tr (DD) OrcID: 0000-0002-68293749 .

Nur OKUR, E.Ü. Ziraat Fakültesi Toprak Bilimi ve Bitki Besleme Bölümü, Bornova, IZMï. E-mail: nur.okur@ege.edu.tr (D) OrcID: 0000-0002-7796-1227. Atıf/Citation: Yağmur B, Okur B, Okur N. Kirece Bir Alternatif Olarak Şlam Uygulamasının Asit Reaksiyonlu Toprakta Biber (Capsicum annuum var. Cerasiforme) Bitkisinin Beslenmesine Etkileri. Tekirdağ Ziraat Fakültesi Dergisi, 18 (4), 636-648.

*Bu çalıșma Yüksek Lisans tezinden özetlenmiștir.

CBu çalışma Tekirdağ Namık Kemal Üniversitesi tarafından Creative Commons Lisansı (https://creativecommons.org/licenses/by-nc/4.0/) kapsamında yayınlanmıştır. Tekirdă̆ 2021
} 


\begin{abstract}
This study was carried out to investigate the liming materials (granule and powder) with the different form, amount and combinations and sugar beet factory waste (vinasse) on $\mathrm{pH}$, mineral matter content of an acid soil and the yield and nutrition of pepper plant. The experiment was carried out in pots under greenhouse conditions. Lime required to neutralize the total acidity of the soil (6.5 from 5.50) was calculated and then the experiment subjects were determined as follows $\mathrm{K}$ (Control), PL (Powder Lime; \%90 $\mathrm{CaCO}_{3}, \% 5 \mathrm{MgCO}_{3}$ ), GL (Granular Lime; \%90 $\mathrm{CaO}$ ), $\mathrm{V}($ Vinasse), $1 / 4 \mathrm{PL}+3 / 4 \mathrm{~V}, 1 / 2 \mathrm{PL}+1 / 2 \mathrm{~V}, 3 / 4 \mathrm{PL}+1 / 4 \mathrm{~V}, 1 / 4 \mathrm{GL}+3 / 4 \mathrm{~V}, 1 / 2 \mathrm{GL}+1 / 2 \mathrm{VL}$ and $3 / 4 \mathrm{GL}+1 / 4 \mathrm{~V}$. To increase $\mathrm{pH}$ of soils, $300 \mathrm{~kg} \cdot \mathrm{da}^{-1}$ lime was applied and then the experiment soils were incubated for one month. N, P, K as basic fertilization was applied by mixing the soil before planting. According to the results; the most effective application in increasing soil $\mathrm{pH}$ was powder lime, and granular lime had the same effect with slime. The $\mathrm{pH}$ of the control soil with a $\mathrm{pH}$ of 5.50 has been increased to 6.42 with TK application and 6.41 with $\mathrm{TK}+1 / 2 \mathrm{~S} \mathrm{~L}$ application. The applications significantly increased the total $\mathrm{N}$, available $\mathrm{P}, \mathrm{Ca}, \mathrm{Fe}$ and $\mathrm{Zn}$ contents of the soil and the total N, P, Fe, Cu, Zn and Mn contents of the plant compared to the control. The first three applications that increase pepper yield showed a ranking as TK $>$ ŞL $>$ VK. According to the results, it determined that vinasse can be used as an alternative lime material in agricultural fields besides lime applications in acid reaction soils.
\end{abstract}

Keywords: pH, Powder lime, Granüle lime, Vinasse, Pepper, Soil, Yield, Plant nutrient 


\section{Giriş}

Toprak pH'sı (reaksiyonu), bitki gelişimi üzerinde doğrudan etkisi olan toprağın fiziksel, kimyasal ve biyolojik süreçleri üzerinde önemli bir etkisi olan bir parametredir. Toprak verimliliği ve bitkisel üretkenlik, toprak pH's1 ile yakından ilişkilidir. Tarımsal üretim genellikle hafif asidik ile hafif alkali toprak reaksiyonlarında gerçekleştirilir ve bu $\mathrm{pH}$ aralığında besin maddeleri topraklarda optimal düzeylerde bulunur. Tüm topraklarda iz elementlerin eriyebilirliği, hareketliliği ve biyo yarayışlılığı, $\mathrm{pH}$ tarafından çok kuvvetli bir şekilde etkilenmektedir. Kuvvetli asit veya alkalin topraklarda besin maddelerinin yarayışılı formları azalır ve bu durum bitki gelişimini kısıtlar. Bitkilerin ekstrem pH düzeylerine toleransları farklılık gösterse de bir çok kültür bitkisi nötrale yakın bir pH'da optimum performans gösterir (Läuchli ve Grattan, 2012). Bitkisel üretim sırasında veya öncesinde ve sonrasında toprak yönetimi ile ilgili tüm yönetim biçimleri (toprağın işlenmesi, gübre veya kireç uygulaması gibi) ve iklim değişkenleri (yağmur gibi), topraktaki $\mathrm{pH}$ değişimi ile yakından ilgilidir. Toprak reaksiyonunun asitleşmesi diğer toprak özelliklerinin de bozulmasına neden olabilmektedir. Bu nedenle gerekli önlemlerle $\mathrm{pH}$ değerlerinin optimum düzeylere getirilmesi gerekmektedir. Aksi takdirde toprakların asitleşmesi sonucu mevcut bitkisel üretimde kayıpların meydana gelme olasıllı̆ı yüksektir.

Asidik toprakların yönetimi, bu toprağın üretim potansiyelinin geri kazanılmasını sağlamak için dolaylı ve doğrudan çeşitli araçların uygulanmasını gerektirir. Doğrudan uygulamalar, optimum bitkisel üretim için toprakların kireçlenmesi ve bazı tarımsal uygulamaların manipülasyonunu içerir (Yirga ve ark., 2019). Kireçleme, asit reaksiyonlu toprakları yönetmende bilinen en önemli yöntemlerinden birisidir. Genelde saf kalsiyum karbonata yakın düzeyde $\mathrm{Ca}$ içermesi nedeniyle, kireç aynı zamanda toprağa önemli miktarda Ca'un girmesine neden olmaktadır. Bir bitki besin maddesi olması nedeniyle kalsiyum, hem biyokimyasal hem de fonksiyonel etkili olup ayrıca bitkinin stres koşullarına dayanıklılığını artırması açısından da önemli bir role sahiptir. Karabulut ve Bellitürk (2013) farklı Mg kaynaklarını uyguladıkları asit reaksiyonlu topraklarda mısır bitkisinin potasyum, kalsiyum ve magnezyum içeriğinin toprak bünyesine göre farklılık gösterdiğini saptamışlardır. Tarım topraklarında genellikle yeteri kadar kalsiyum bulunmasına rağmen asit reaksiyonlu ve yıkanma özelliği yüksek kum bünyeli ve baz doygunluğu düşük topraklarda yetiştirilen bitkilerde kalsiyum eksikliği ortaya çıkabilmektedir (Karaman ve ark., 2012).

Asit topraklara verilecek kireç miktarını hesaplarken toprağın pH'sının yanında değişebilir katyonlar ve baz doygunluk oranın da bilinmesi gerekir (Altınbaş ve ark., 2016). Ayrıca toprağın kil tipi, organik madde içeriği, bünyesi, bitkinin $\mathrm{pH}$ isteği, uygulanacak kireçleme materyalinin saflık derecesi ve parça büyüklüğü de önemlidir. Tarım topraklarının kireçlenmesinde; kireç, dolomit, kalsiyum oksit ve kalsiyum hidroksittir en çok kullanılan kireçleme materyalleridir. Kireçleme amacıyla kullanılan materyallerde $\mathrm{Ca}$ ve $\mathrm{Mg}$ elementlerinin bulunması yeterli olmayıp, aynı zamanda mevcut anyonların da bitki besin elementlerin alınabilirliğini sağlayan toprak çözeltisinde bulunan hidrojen ve alüminyum iyonlarının aktivitesini azaltacak özelliğe sahip olması da gerekmektedir. Başka bir ifadeyle kireçlemede kullanılan kimyasalın toprak çözeltisinde bulunan iyonları nötrleştirmesi gerekmektedir (Msimbira ve Smith, 2020). Asit reaksiyonlu toprakların islahında kireç, dolomit, kalsiyum oksit ve kalsiyum hidroksit gibi kireçleme materyalleri dışında ayrıca çimento, çelik ve kağıt endüstrisi atıkları, bazı deniz canlılarının ve salyangoz gibi hayvanların kabukları, kalsiyum ve magnezyum silikat içeren cüruf, şeker fabrikası atığı şlam ve doğal kalsitik kireç gibi alternatif kaynaklar da kullanılmaktadır (GonzálezFernández ve ark., 2004; Castro ve Crusciol, 2013).

Şeker pancarını işleyerek şeker elde edilmesi esnasında şeker fabrikası sanayi atığı olarak ortaya çıkan şlam, ham şerbetin kireç sütü $(\mathrm{CaO})$ ile muamele edilmesi sonucunda elde edilen ve organik ve inorganik bileşiklerden oluşan bir maddedir (Özen ve Arat, 1999, Özyazıc1, 2014). Bu atık ya sulandırılarak derelere verilmekte veya çöktürme çukurlarında toplanmaktadır (Aksoy ve Danışman, 1989). Şlam, $\mathrm{CaCO}_{3}$ (kalsiyum karbonat \% 70) ve organik madde içeriği yüksek bir atık materyaldir. Bu nedenle şlamın asit reaksiyonlu toprakların sslahında kullanılabilme potansiyeli bulunmaktadır. Böylece bir atık durumunda bulunan şlamın çevre kirliliğine neden olmadan tarım topraklarında değerlendirilmesi söz konusu olacaktır.

$\mathrm{Bu}$ çalışmada, asit reaksiyonlu topraklarda öncelikle $\mathrm{pH}$ derecesini optimal düzeye getirmek için uygulanabilecek kireç formlarının belirlenmesi, ve ayrıca şeker sanayi atık ürünü olarak bilinen şlamın kireçleme materyallerine alternatif bir materyal olup olamayacağı ve tüm bu uygulamaların biber bitkisinin gelişimi üzerine etkileri araştırılmıştır. 


\section{Materyal ve Metot}

\subsection{Materyal}

İzmir ili Ödemiş ilçesindeki bir üretici tarlasından 0-30 cm derinliğinden alınan yüzey toprağı araştırmanın toprak materyalini oluşturmuştur. Hava kurusu hale getirilen ve elenen topraktan fiziksel ve kimyasal analizler için yeterli miktar ayrıldıktan sonra geri kalan kısmı saksı denemesinde kullanılmıştır. Orta derecede asit reaksiyona sahip deneme toprağına ait analiz sonuçları Tablo 1 'de verilmiştir.

Tablo 1. Toprak örnĕ̆inin fiziksel ve kimyasal özellikleri

Table 1. Physical and chemical properties of soil sample

\begin{tabular}{|c|c|c|c|}
\hline \multicolumn{2}{|c|}{ Fiziksel ve Kimyasal Özellikler } & Sonuç & Yorum \\
\hline \multicolumn{2}{|c|}{$\mathrm{pH}(1: 2.5 \mathrm{su})$} & 5.55 & Orta Derecede Asit \\
\hline \multicolumn{2}{|c|}{ Toplam Tuz (\%) } & 0.037 & Sorun yok \\
\hline \multicolumn{2}{|c|}{ Kireç $\left(\mathrm{CaCO}_{3}\right)(\%)$} & 1.21 & Kireççe fakir \\
\hline \multicolumn{2}{|c|}{$\operatorname{Kum}(\%)$} & 72.00 & \\
\hline \multicolumn{2}{|c|}{ Silt (\%) } & 14.00 & \\
\hline \multicolumn{2}{|c|}{ Kil (\%) } & 14.00 & \\
\hline \multicolumn{2}{|c|}{ Bünye } & Kum-Tin & \\
\hline \multicolumn{2}{|c|}{ Toplam Organik Madde (\%) } & 1.94 & Fakir \\
\hline \multicolumn{2}{|c|}{ Toplam Azot (N) (\%) } & 0.086 & Orta \\
\hline \multirow{9}{*}{ 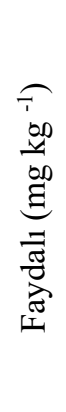 } & Fosfor $(\mathrm{P})$ & 10.80 & Yeterli \\
\hline & Potasyum (K) & 178 & Fakir \\
\hline & Kalsiyum (Ca) & 960 & Orta \\
\hline & Magnezyum (Mg) & 70.0 & Yeterli \\
\hline & Sodyum $(\mathrm{Na})$ & 19.80 & Sorunsuz \\
\hline & $\operatorname{Demir}(\mathrm{Fe})$ & 7.16 & Yeterli \\
\hline & Çinko (Zn) & 1.27 & Yeterli \\
\hline & Bakır $(\mathrm{Cu})$ & 0.94 & Yeterli \\
\hline & Mangan (Mn) & 17.91 & Yeterli \\
\hline
\end{tabular}

Araştırmada kullanılan kireç materyalleri( \%90 saflıkta granül $(\mathrm{CaO})$ ve toz $\left(\mathrm{CaCO}_{3}+\% 5 \mathrm{MgCO}_{3}\right)$ tarım kireci) Kimtaş Kireç San. Tic. A.Ş. firmasından, şlam ise Susurluk Şeker Fabrikasından temin edilmiştir. Kuvvetli alkalin reaksiyona sahip şlam materyalinin (Özyazıcı, 2014) diğer kimyasal özellikleri Tablo 2'de verilmiştir.

Tablo 2. Kireçleme materyali olarak kullanılan şlamın kimyasal özellikleri

Table 2. Chemical properties of vinasse used as liming material

\begin{tabular}{|c|c|c|}
\hline Parametreler & Sonuç & Yorum \\
\hline $\mathrm{pH}$ & 9.45 & Kuvvetli alkalin \\
\hline Toplam Tuz (\%) & 0.046 & Tuzsuz \\
\hline Kireç $\left(\mathrm{CaCO}_{3}\right)(\%)$ & 80.41 & Çok fazla Kireçli \\
\hline Toplam Organik Madde (\%) & 3.40 & İyi \\
\hline Toplam Azot (N) (\%) & 0.045 & Fakir \\
\hline Faydalı Fosfor (P) (mg kg $\left.{ }^{-1}\right)$ & 2.20 & Yetersiz \\
\hline Faydalı Potasyum (K) $\left(\mathrm{mg} \mathrm{kg}^{-1}\right)$ & 78.4 & Yetersiz \\
\hline Faydalı Kalsiyum (Ca)(mg kg $\left.{ }^{-1}\right)$ & 5242 & Yüksek \\
\hline Faydalı Magnezyum $(\mathrm{Mg})\left(\mathrm{mg} \mathrm{kg}^{-1}\right)$ & 157.4 & Yeterli \\
\hline Faydalı Sodyum (Na) $\left(\mathrm{mg} \mathrm{kg}^{-1}\right)$ & 29.18 & Yeterli \\
\hline Faydalı Demir $(\mathrm{Fe})\left(\mathrm{mg} \mathrm{kg}^{-1}\right)$ & 26.04 & Yeterli \\
\hline Faydalı Çinko (Zn) $\left(\mathrm{mg} \mathrm{kg}^{-1}\right)$ & 0.12 & Yetersiz \\
\hline Faydalı Bakır (Cu) $\left(\mathrm{mg} \mathrm{kg}^{-1}\right)$ & 0.31 & Yetersiz \\
\hline Faydalı Mangan (Mn) $\left(\mathrm{mg} \mathrm{kg}^{-1}\right)$ & 2.40 & Yeterli \\
\hline
\end{tabular}


Araştırmanın bitki materyalini ise meyveleri oval, yuvarlak, küre şeklinde veya uzunca yassı sivribiber şeklinde olan Capsicum annuum var. cerasiforme çeşidi kiraz biberi oluşturmuştur. Arnavut biberi olarak adlandırılan bu biber çeşidinin meyvelerinin uzunlukları 2-3 cm olup çapları 1-1.5 cm arasındadır.

\subsection{Yöntem}

\subsubsection{Saksı denemesi}

Orta derecede asit reaksiyona sahip deneme toprağının kireç ihtiyacı Dunn yöntemine göre belirlenmiştir. Bu tip topraklara uygulanacak kireç ihtiyacının belirlenmesinde en çok kullanılan ve en uygun yöntem bu yöntemdir (Dunn, 1943). Araştırma toprağının kireç ihtiyacı hesaplanmasında 5.55 olan toprak pH'sını 6.5'a çıkarmak amaçlanmıştır. Buna göre araştırmada uygulanan deneme konuları ve uygulanan kireç miktarları ile oranlar Tablo 3'de verilmiştir

Tablo 3. Deneme konulart ve kireç materyallerinin uygulama miktarlart Table 3. The experiment subjects and the amount of applications of liming materials

\begin{tabular}{ll}
\hline Uygulamalar & Uygulama miktarları $\left(\mathrm{kg} . \mathrm{da}^{-1}\right)$ \\
\hline $1-\mathrm{K}$ (Kontrol) & 0 \\
$2-1 / 4 \mathrm{TK}+3 / 4$ ŞL & $75+280$ \\
$3-1 / 2 \mathrm{TK}+1 / 2$ ŞL & $150+187$ \\
$4-3 / 4 \mathrm{TK}+1 / 4$ ŞL & $22.5+287$ \\
$5-1 / 4 \mathrm{GK}+3 / 4$ ŞL & $75+280$ \\
$6-1 / 2 \mathrm{GK}+1 / 2$ ŞL & $150+187$ \\
$7-3 / 4 \mathrm{GK}+1 / 4$ SSL & $22.5+280$ \\
$8-\mathrm{TK}$ (Toz Kireç) & 300 \\
9-GK (Granül Kireç) & 300 \\
$10-$ ŞL (Şlam) & 373 \\
\hline
\end{tabular}

Deneme $4 \mathrm{~kg}$ toprak alan toplam 30 adet plastik saksıda sera koşularında yürütülmüş, tesadüf parselleri deneme desenine planlanmıştır. Tablo 3'de verilen kireç ve şlam miktarları uygulandıktan sonra saksılar 30 günlük bir inkübasyona bırakılmışlardır. Saksı ağırlıkları iki gün ara ile tartılarak tarla kapasitesine gelinceye kadar, eksik olan su miktarı saksılara ilave edilmiştir. Biber tohumları fide yetiştirme ortamı olan torf-perlit ortamında çimlendirilip fide haline geldikten sonra uygulama saksılarının her birine iki adet olacak şekilde 30 günlük inkübasyon süresi sonunda şaşırtılmıştır. Fide şaşırtması yapılmadan önce saksılara temel gübreleme olarak amonyum sülfat $(\% 21 \mathrm{~N})$, TSP $\left(\% 43 \mathrm{P}_{2} \mathrm{O}_{5}\right)$ ve potasyum sülfat $\left(\% 50 \mathrm{~K}_{2} \mathrm{O}\right)$ gübreleri kullanılarak; $200 \mathrm{mg} \cdot \mathrm{kg}^{-1} \mathrm{~N}$; $100 \mathrm{mg} \cdot \mathrm{kg}^{-1} \quad \mathrm{P}_{2} \mathrm{O}_{5}$ ve $250 \mathrm{mg} \cdot \mathrm{kg}^{-1} \mathrm{~K}_{2} \mathrm{O}$ olacak şekilde gübreler toprakla iyice karıştırılarak uygulanmıştır. Ayrıca daha sonra üst gübre olarak her saksıya $50 \mathrm{mg} \cdot \mathrm{kg}^{-1} \mathrm{~N}$ olacak şekilde amonyum nitrat gübresi (\%33 $\left.\mathrm{N}\right)$ uygulanmıştır. Araştırmada uygulamaların yapıldığı saksılar her gün tartılmak suretiyle başlangıçta su tutma kapasitesinin \% 60’1 olacak şekilde eksilen su verilerek sulama yapılmış ve vejetasyon süresi içerisinde bu miktar su tutma kapasitesinin \%80'ine çıkarılmıştır. Sera koşullarında 4 ay sürdürülen çalışmada saksı verimini belirlemek için saksılardan hasat zamanlarında toplanan biber meyveleri tartılarak meyve verimleri belirlenmiş ve ayrıca uygun yaprak alma döneminde saksılardan alınan yaprak örneklerinde makro ve mikro besin element miktarları tespit edilmiştir (Şekil 1 ve 2). Ayrıca deneme sonunda alınan toprak örneklerinin de pH ile birlikte makro ve mikro besin element miktarları belirlenmiştir.

\subsubsection{Bitki örneklerinin kimyasal analiz yöntemleri}

Araştırmada konusu saksılardan tekerrürlü olarak alınan yaprak örnekleri yıkanıp temizlendikten sonra 65 $0^{\circ} \mathrm{C}$ 'de sabit ağırlığa ulaşıncaya kurutma dolabında bekletilerek kurutulmuştur. Kurutma sonucunda sabit ağırlığa erişen yaprak örnekleri ögütülerek analize hazır hale getirilmiştir (Kacar ve İnal, 2008). Analize hazır hale getirilen bitki örneklerinde makro ve mikro besin elementleri sırasıyla, toplam azot makro Kjeldahl yöntemiyle; yaş yakma yöntemi uygulanarak elde edilen bitki ekstraktlarında; toplam $\mathrm{P}$ kolorimetre, toplam $\mathrm{K}, \mathrm{Ca}, \mathrm{Na}$ alev fotometresi, toplam $\mathrm{Mg}, \mathrm{Fe} ; \mathrm{Cu}, \mathrm{Zn}$ ve $\mathrm{Mn}$ ise atomik absorpsiyon spektrofotometrede okunarak belirlenmiştir (Kacar, ve İnal 2008). 
JOTAF/ Journal of Tekirdag Agricultural Faculty, 2021, 18(4)
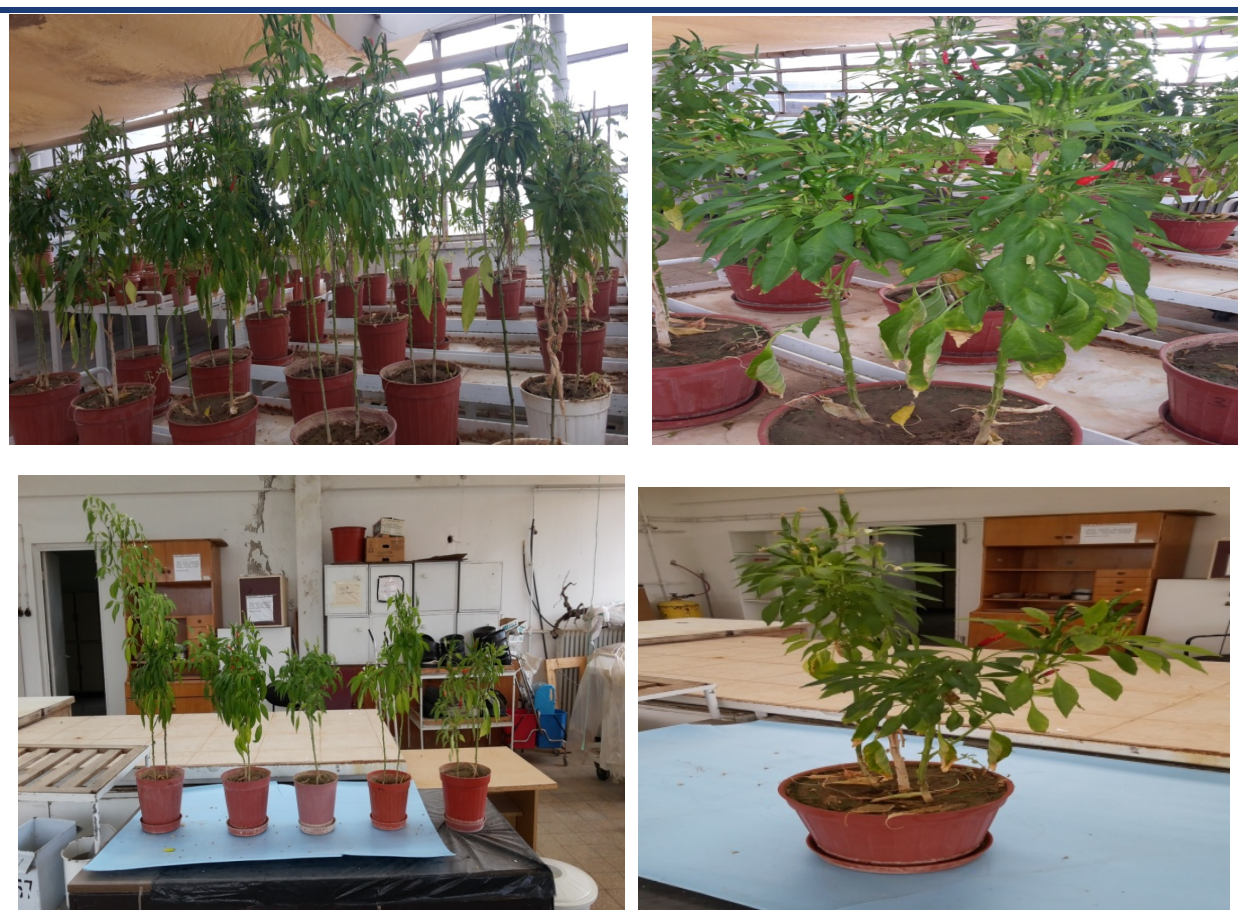

Figure 1. Pepper plants in the pot experiment

Şekil 1. Saksı denemesi biber bitkileri
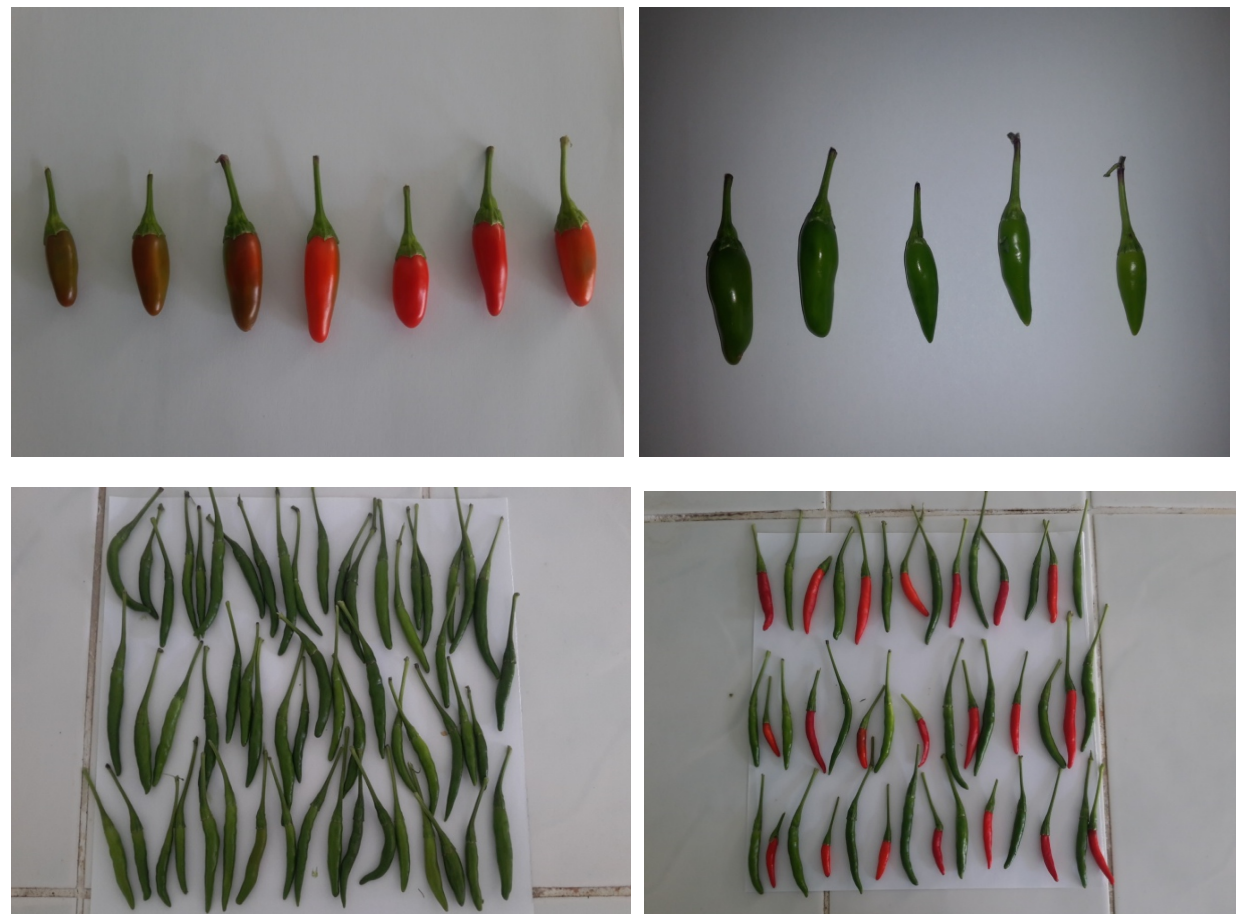

Figure 2. Pepper fruits in the pot experiment

Şekil 2. Saksı denemesi biber meyveleri

\subsubsection{Toprak örneklerinin kimyasal analiz yöntemleri}

Hasat sonrası deneme saksılarından alınan toprak örneklerinde fiziksel ve kimyasal analizler yapılmıştır. pH ve suda çözünür toplam tuz saf su ile sature edilen $(1: 2.5)$ saturasyon çamurunda cam elektrotlu pH metre ve sature toprak macununun elektriksel geçirgenliğinin $\mathrm{EC}$-metre cihazında ölçülmesi ile kireç $\left(\mathrm{CaCO}_{3}\right)$ ise volümetrik olarak Scheibler kalsimetresi ile belirlenmiştir. Toprak örneklerinde bünye (kum, mil, kil) hidrometrik yöntemi ile organik madde yaş yakma yöntemi uygulanarak saptanmıştır. Toplam N, Kjeldahl yöntemi ile faydalı P, sodyum 
Kirece Bir Alternatif Olarak Şlam Uygulamasının Asit Reaksiyonlu Toprakta Biber (Capsicum annuum var. Cerasiforme) Bitkisinin Beslenmesine Etkileri bikarbonatın kullanıldığı ekstraksiyon yöntemi ile kolorimetrik olarak, faydalı K ve Ca, $1 \mathrm{~N}$ Amonyum Asetat $(\mathrm{pH}=7,0)$ çözelti kullanılarak elde edilen ekstraktın alev fotometresinde okunması ile, aynı ekstrakta magnezyum ise atomik absorpsiyon spektrofotometresinde ölçülerek, faydalı demir, bakır, çinko ve mangan içerikleri toprak örneklerinin DTPA + TEA ile ekstraksiyonu sonrası süzügün atomik absorpsiyon spektrometrede okunması suretiyle tayin edilmiştir (Kacar, 2016)

\subsection{4. İstatistik değerlendirme yöntemi}

Kireç uygulamalarının bağımlı değişkenler üzerindeki etkisi faktöriyel olarak ANOVA analizi ile test edilmiştir. Ortalama değerlerin karşılaştırması ise LSD’e göre yapılmıştır. Tüm verilerin istatistiki analizi IBM SPSS Statistics 15.0 programında yapılmıştır.

\section{Araştırma Sonuçları ve Tartışma}

\section{1. şlam uygulamalarının toprak reaksiyonu ile makro ve mikro element miktarları üzerine etkisi}

Farklı kireçleme materyalleri (granül-toz kireç) ve şeker fabrikası atığı şlam uygulamalarının toprak reaksiyonu $(\mathrm{pH})$ ile toprakların toplam $\mathrm{N}$, faydalı $\mathrm{P}$ ve Ca içeriği üzerine etkisi istatistiki anlamda önemli olurken, faydalı $\mathrm{K}$ ve Mg miktarları üzerinde herhangi bir etkisi ortaya çıkmamıştır (Tablo 4).

Tablo 4. Kireç ve şlam uygulamalarının toprağın pH ve makro element miktarı üzerine etkisi Table 4. The effect of lime and vinasse applications on pH and the content of macroelements of soil

\begin{tabular}{|c|c|c|c|c|c|c|}
\hline \multirow{2}{*}{ Uygulamalar } & \multirow{2}{*}{$\mathrm{pH}$} & \multirow{2}{*}{$\begin{array}{l}\text { Toplam } \\
\text { N (\%) }\end{array}$} & \multicolumn{4}{|c|}{ Faydalı $\left(\mathrm{mg} \cdot \mathrm{kg}^{-1}\right)$} \\
\hline & & & $\mathrm{P}$ & $\mathrm{K}$ & $\mathrm{Ca}$ & $\mathrm{Mg}$ \\
\hline Kontrol & $5.50 \mathrm{~d}$ & $0.085 \mathrm{c}$ & $9.01 \mathrm{~d}$ & 160 & $920 \mathrm{~d}$ & 61 \\
\hline 1/4 Toz Kireç+3/4 Şlam & $6.40 \mathrm{a}$ & $0.101 \mathrm{~b}$ & $9.13 \mathrm{ab}$ & 162 & $1084 \mathrm{ab}$ & 64 \\
\hline 1/2 Toz Kireç+1/2 Şlam & $\underline{6.41 \mathrm{a}}$ & $0.107 \mathrm{a}$ & $9.14 \mathrm{a}$ & $\underline{165}$ & $1070 \mathrm{ab}$ & 65 \\
\hline 3/4 Toz Kireç+1/4 Şlam & $6.36 \mathrm{~b}$ & $0.105 \mathrm{ab}$ & $9.14 \mathrm{a}$ & 163 & $1042 \mathrm{c}$ & 65 \\
\hline $1 / 4$ Granül Kireç+3/4 Şlam & $6.35 \mathrm{~b}$ & $0.102 \mathrm{~b}$ & $9.08 \mathrm{c}$ & 162 & $1050 \mathrm{c}$ & $\underline{67}$ \\
\hline 1/2 Granül Kireç +1/2 Şlam & $6.34 \mathrm{~b}$ & $0.104 \mathrm{ab}$ & $9.10 \mathrm{~b}$ & 162 & $1062 \mathrm{~b}$ & 62 \\
\hline 3/4 Granül Kireç +1/4 Şlam & $6.29 \mathrm{c}$ & $0.100 \mathrm{~b}$ & $9.12 \mathrm{ab}$ & 161 & $1070 \mathrm{ab}$ & 62 \\
\hline Toz Kireç & $\underline{6.42 \mathrm{a}}$ & $\underline{0.106 \mathrm{a}}$ & $9.12 \mathrm{ab}$ & 160 & $1064 \mathrm{~b}$ & 63 \\
\hline Granül Kireç & $6.34 \mathrm{~b}$ & $0.100 \mathrm{~b}$ & $9.10 \mathrm{~b}$ & 161 & $1078 \mathrm{ab}$ & 62 \\
\hline Şlam & $6.36 \mathrm{~b}$ & $0.104 \mathrm{ab}$ & $9.14 \mathrm{a}$ & 160 & $1090 \mathrm{a}$ & 65 \\
\hline$L S D$ & & $*$ & $*$ & öd & $* *$ & öd \\
\hline
\end{tabular}

Kireç ve şlam uygulamaları toprak pH'sını kontrole göre artırmıştır. En yüksek artışlar TK (6.42), 1/4 TK+3/4 ŞL (6.40) ve 1/2 TK+1/2 ŞL (6.41) uygulamalarınsa tespit edilmiştir. Toprak pH'sının yükselmesinde en büyük etkiyi toz kirecin yaptığı, granül kirecin ise şlam ile aynı etkiyi gösterdiği anlaşılmıştır. Şlam ve kireç uygulamaları kontrole göre toprakta 0.8-0.9 birim pH artış sağlamıştır. Araştırmada toprakların pH'sının 6.5 olacak şekilde kireçleme materyalleri uygulanması planlanmış ve bu hedefe az bir farkla yaklaşılmıştır. Ülgen (1967) ise Doğu Karadeniz Bölgesi topraklarında yaptığı çalışmada toprak pH’sını yükseltmede şlamın kireçten daha etkili olduğunu saptamıştır.

Kireç ve şlam uygulamaları toprakların toplam N, faydalı $\mathrm{P}$ ve Ca içeriklerini kontrole oranla artırmıştır. En yüksek toplam azot TK ve $1 / 2 \mathrm{TK}+1 / 2$ ŞL uygulamalarında, en yüksek faydalı fosfor ŞL, $1 / 2 \mathrm{TK}+1 / 2$ ŞL ve $3 / 4 \mathrm{TK}+1 / 4$ ŞL uygulamalarında ve en yüksek faydalı $\mathrm{Ca}$ ise ŞL uygulamasında saptanmıştır (Tablo 4). Toprak pH'sının artmasına bağlı olarak topraktaki mikrobiyal aktivitenin ve dolayısıyla enzim aktivitesi ve mineralizasyon olaylarının artmasıyla toprak çözeltisine geçen mineral madde miktarı da artabilmektedir. Tevali (2021) şlam kompostu uygulamalarının topraktaki üreaz, alkalin fosfotaz ve $\beta$-Glukozidaz enzim aktivitelerini artırdığını ve bu artışa bağlı olarak topraktaki değişebilir K hariç besin madde miktarlarının arttığını bildirmiştir. Benzer sonuç bizim çalışmamızda da ortaya çıkmış ve faydalı K yanında Mg'da şlam uygulamalarından etkilenmemiştir. Toprak pH'sı ile topraklardaki mineral madde miktarları arasındaki korelasyon analizi sonucu da pH ile toplam azot, fosfor 
ve kalsiyum arasında \% 1 düzeyinde önemli ilişkiler ortaya çıkarken, $\mathrm{pH}$ ile $\mathrm{K}$ ve $\mathrm{Mg}$ arasında ise bir ilişki saptanamamıştır (Tablo 5). Sezen (1981) kireçleme ile yükselen pH'a bağlı olarak topraktaki K yarayışlılığının azaldığını tespit ederken, Özyazıcı ve ark. ise (2014), artan şlam uygulamalarına paralel olarak toprak reaksiyonu $(\mathrm{pH})$ ile yarayışlı $\mathrm{P}, \mathrm{K}$ ve değişebilir $\mathrm{Ca}$ arasında pozitif ilişkilerin ortaya çıktığını ileri sürmüşlerdir.

\section{Tablo 5. Toprak pH's ile toprağın mineral madde kapsamı arasındaki ilişkiler ve korelasyon katsayıları}

Table 5. Correlations between soil $\mathrm{pH}$ and soil elements

\begin{tabular}{ll}
\hline Toprak Elementleri & Toprak pH's1 \\
\hline Toplam N & $0.923^{* *}$ \\
Faydalı $\mathrm{P}$ & $0.896^{* *}$ \\
Faydalı $\mathrm{K}$ & öd \\
Faydalı $\mathrm{Ca}$ & $0.964^{* *}$ \\
Faydalı $\mathrm{Mg}$ & öd \\
Faydalı $\mathrm{Fe}$ & $0.928^{* *}$ \\
Faydalı Çinko & öd \\
Faydalı Bakır & $-0.748^{*}$ \\
Faydalı Mangan & öd \\
\hline$*: \mathrm{P}<0.05,{ }^{* *}: \mathrm{P}<.01$ düzeyinde önemli, öd: önemli değil
\end{tabular}

Granül ve toz kireç ile şlam uygulamalarının toprağın faydalı mikro elementlerinden Fe ve Zn içeriğine etkisi istatistiki anlamda önemli olurken, faydalı $\mathrm{Cu}$ ve $\mathrm{Mn}$ üzerinde ise herhangi bir etkisi ortaya çıkmamıştır (Tablo 6).

Tablo 6. Kireç ve şlam uygulamalarının toprağın mikro element içeriği üzerine etkisi

Table 6. The effect of lime and vinasse applications on the content of microelements of soil

\begin{tabular}{|c|c|c|c|c|}
\hline \multirow{2}{*}{ Uygulamalar } & \multicolumn{4}{|c|}{ Faydalı $\left(\mathrm{mg} \cdot \mathrm{kg}^{-1}\right)$} \\
\hline & $\mathrm{Fe}$ & $\mathrm{Cu}$ & $\mathrm{Zn}$ & $\mathrm{Mn}$ \\
\hline Kontrol & $7.42 \mathrm{~g}$ & 0.81 & $1.24 \mathrm{~d}$ & 17.11 \\
\hline 1/4 Toz Kireç+3/4 Şlam & $9.22 \mathrm{c}$ & 0.81 & $1.27 \mathrm{~d}$ & 17.12 \\
\hline 1⁄2 Toz Kireç+1/2 Şlam & $\underline{9.70} \mathrm{a}$ & 0.81 & $1.62 \mathrm{a}$ & 17.08 \\
\hline 3/4 Toz Kireç+1/4 Şlam & $9.54 \mathrm{~b}$ & 0.82 & $1.54 \mathrm{ab}$ & 17.13 \\
\hline 1/4 Granül Kireç+3/4 Şlam & $9.51 \mathrm{~b}$ & 0.80 & $1.22 \mathrm{~d}$ & $\underline{17.96}$ \\
\hline $1 / 2$ Granül Kireç $+1 / 2$ Şlam & $9.01 \mathrm{e}$ & 0.80 & $1.34 \mathrm{c}$ & $\overline{17.12}$ \\
\hline $3 / 4$ Granül Kireç +1/4 Şlam & $9.19 \mathrm{c}$ & 0.81 & $1.21 \mathrm{~d}$ & 17.10 \\
\hline Toz Kireç & $7.93 \mathrm{f}$ & 0.82 & $1.22 \mathrm{~d}$ & 17.64 \\
\hline Granül Kireç & $7.43 \mathrm{~g}$ & 0.81 & $1.24 \mathrm{~d}$ & 17.15 \\
\hline Şlam & $9.10 \mathrm{~d}$ & $\underline{0.83}$ & $1.45 \mathrm{~b}$ & 17.87 \\
\hline LSD & $* *$ & öd & $* *$ & öd \\
\hline
\end{tabular}

Kireç ve şlam uygulamaları toprakların faydalı $\mathrm{Fe}$ ve $\mathrm{Zn}$ içeriklerini kontrole oranla önemli miktarlarda artırmıştır. En yüksek faydalı $\mathrm{Fe}$ ve $\mathrm{Zn}$ konsantrasyonları 1 $12 \mathrm{TK}+1 / 2$ S S uygulamasında saptanmıştır. Topraklardaki mikro elementlerin azami yarayışlı miktarları genellikle 5.0-6.5 pH arasında bulunmaktadır. Daha yüksek ve daha düşük $\mathrm{pH}$ derecelerinde ise yarayışlı miktarlar değişmektedir. Araştırma topraklarının pH'sı 6.4'ü geçmediği , mikrobiyal aktivite için daha uygun koşullar ortaya çıktı̆̆ı, şlamın organik madde ve bir miktar bitki besin maddesi içermesi, ayrıca biber bitkisi yetiştirme ortamı toprağın mikrobiyal aktivitesi üzerine de etki yapabileceği için mikro element miktarlarında bir yükselme meydana geldiği düşünülmektedir. Benzer sonuçlar Kumar ve Chopra (2010) tarafından da bulunmuş ve Hindistan'da şeker fabrikası atıklarının toprağa uygulanması ile topraktaki Fe, $\mathrm{Zn}, \mathrm{Cd}, \mathrm{Cu}, \mathrm{Pb}$ and $\mathrm{Cr}$ miktarlarının arttı̆̆ı rapor edilmiştir.

\subsection{Kireç materyalleri ve şlam uygulamalarının biber bitkisi yapraklarının besin elementi içeriğine etkisi}

Kireç ve şlam uygulamalarının biber bitkisi yapraklarındaki tüm makro ve mikro element miktarları üzerindeki etkisi istatistiki anlamda önemli çıkmıştır. Kireç ve şlam uygulamaları yaprakların N ve P içeriklerini kontrole 
Kirece Bir Alternatif Olarak Şlam Uygulamasının Asit Reaksiyonlu Toprakta Biber (Capsicum annuum var. Cerasiforme) Bitkisinin Beslenmesine Etkileri oranla önemli miktarlarda artırmıştır. En yüksek toplam azot TK uygulamasında, en yüksek toplam P ise ŞL ve 1/2 $\mathrm{TK}+1 / 2$ ŞL uygulamalarında saptanmıştır. Biber bitkisinin $\mathrm{K}$ içeriği sadece $\mathrm{TK}$, ŞL ve $1 / 4 \mathrm{TK}+3 / 4 \mathrm{~S} \mathrm{~L}$ uygulamalarında artmış, bu uygulamalar dışındaki tüm uygulamalar kontrol uygulaması ile aynı istatistiki grupta yer almıştır (Tablo 7). Bu durum kireçlemeyle birlikte K’un yarayışlılığındaki azalmadan kaynaklanmış (CaxK interaksiynu) olabilir. Bitkinin $\mathrm{Ca}$ ve $\mathrm{Mg}$ içerikleri üzerine ise kireç materyallerin tek başına uygulamaları, kombine uygulamalara oranla daha fazla etkili olmuştur.

Tablo 7. Toz ve granül kireç ile şlam uygulamalarının biber bitkisinin makro element içeriğine etkisi

Table 7. The effect of lime(powder and granüle) and vinasse applications on the content of macroelements of pepper

\begin{tabular}{lccccc}
\hline \multicolumn{6}{c}{ Toplam (\%) } \\
\hline Uygulamalar & $\mathrm{N}$ & $\mathrm{P}$ & $\mathrm{K}$ & $\mathrm{Ca}$ & $\mathrm{Mg}$ \\
\hline Kontrol & $3.55 \mathrm{~g}$ & $0.36 \mathrm{e}$ & $3.10 \mathrm{~b}$ & $2.50 \mathrm{ab}$ & $0.40 \mathrm{~d}-\mathrm{f}$ \\
1/4 Toz Kireç+3/4 Şlam & $3.91 \mathrm{~cd}$ & $0.65 \mathrm{ab}$ & $\underline{4.36 \mathrm{a}}$ & $2.02 \mathrm{c}-\mathrm{e}$ & $0.50 \mathrm{~cd}$ \\
1/2 Toz Kireç+1/2 Şlam & $3.93 \mathrm{bc}$ & $\underline{0.68 \mathrm{a}}$ & $3.09 \mathrm{~b}$ & $2.06 \mathrm{c}-\mathrm{e}$ & $0.50 \mathrm{~cd}$ \\
3/4 Toz Kireç+1/4 Şlam & $3.90 \mathrm{~cd}$ & $0.66 \mathrm{ab}$ & $3.20 \mathrm{~b}$ & $2.09 \mathrm{~cd}$ & $0.48 \mathrm{c}-\mathrm{e}$ \\
1/4 Granül Kireç+3/4 Şlam & $3.75 \mathrm{ef}$ & $0.55 \mathrm{~cd}$ & $2.79 \mathrm{~b}$ & $1.90 \mathrm{c}-\mathrm{f}$ & $0.46 \mathrm{c}-\mathrm{f}$ \\
1/2 Granül Kireç +1/2 Şlam & $3.83 \mathrm{de}$ & $0.58 \mathrm{bc}$ & $2.79 \mathrm{~b}$ & $1.75 \mathrm{~d}-\mathrm{g}$ & $0.36 \mathrm{f}$ \\
3/4 Granül Kireç +1/4 Şlam & $3.81 \mathrm{de}$ & $0.48 \mathrm{~d}$ & $3.04 \mathrm{~b}$ & $1.72 \mathrm{e}-\mathrm{h}$ & $0.39 \mathrm{ef}$ \\
Toz Kireç & $\underline{4.46 \mathrm{a}}$ & $0.67 \mathrm{ab}$ & $\underline{4.15 \mathrm{a}}$ & $\underline{2.77 \mathrm{a}}$ & $0.77 \mathrm{~b}$ \\
Granül Kireç & $3.65 \mathrm{f}$ & $0.66 \mathrm{ab}$ & $3.02 \mathrm{~b}$ & $\underline{2.76 \mathrm{a}}$ & $0.51 \mathrm{c}$ \\
Şlam & $4.02 \mathrm{~b}$ & $\underline{0.69 \mathrm{a}}$ & $\underline{4.46 \mathrm{a}}$ & $2.19 \mathrm{bc}$ & $\underline{0.89 \mathrm{a}}$ \\
\hline LSD & $*$ & $*$ & $* *$ & $*$ & $*$ \\
\hline Aynı harfle gösterilen ortalamalar arasındaki farkl1lık önemli değildir, \\
*: P<0.05 düzeyinde önemli farklılık, **: P<.01 düzeyinde önemli farklılık, öd: önemli değil
\end{tabular}

Kireç ve şlam uygulamaları mikro elementlerin tümünü kontrole oranla önemli oranlarda artırmıştır. En yüksek Fe ve Zn miktarları TK uygulamasında, en yüksek Cu miktarı ŞL ve en yüksek Mn miktarları ise ŞL ve 1/4 TK+3/4 ŞL uygulamalarında ortaya çıkmıştır (Tablo 8).

Tablo 8. Toz ve granül kireç ile şlam uygulamalarının biber bitkisinin mikro element içeriğine etkisi

Table 8. The effect of lime (Powder and granüle) and vinasse applications on the content of microelements of pepper

\begin{tabular}{lcccc}
\hline & \multicolumn{4}{c}{ Toplam $\left(\mathrm{mg} \mathrm{kg}^{-1}\right)$} \\
\hline \multicolumn{1}{c}{ Uygulamalar } & $\mathrm{Fe}$ & $\mathrm{Cu}$ & $\mathrm{Zn}$ & $\mathrm{Mn}$ \\
\hline Kontrol & $70.37 \mathrm{~g}$ & $7.74 \mathrm{e}$ & $60.33 \mathrm{e}$ & $68.19 \mathrm{e}$ \\
1/4 Toz Kireç+3/4 Şlam & $95.13 \mathrm{~b}$ & $9.17 \mathrm{~cd}$ & $67.98 \mathrm{~cd}$ & $80.43 \mathrm{a}$ \\
1/2 Toz Kireç+1/2 Şlam & $97.44 \mathrm{ab}$ & $9.61 \mathrm{c}$ & $77.76 \mathrm{~b}$ & $77.37 \mathrm{~b}$ \\
3/4 Toz Kireç+1/4 Şlam & $81.87 \mathrm{~d}$ & $9.37 \mathrm{c}$ & $69.24 \mathrm{~cd}$ & $74.86 \mathrm{c}$ \\
1/4 Granül Kireç+3/4 Şlam & $84.99 \mathrm{~d}$ & $8.93 \mathrm{~cd}$ & $64.56 \mathrm{de}$ & $73.22 \mathrm{~d}$ \\
1/2 Granül Kireç +1/2 Şlam & $82.96 \mathrm{~d}$ & $9.01 \mathrm{~cd}$ & $69.25 \mathrm{~cd}$ & $71.91 \mathrm{e}$ \\
3/4 Granül Kireç +1/4 Şlam & $75.11 \mathrm{f}$ & $8.34 \mathrm{de}$ & $68.79 \mathrm{~cd}$ & $72.56 \mathrm{de}$ \\
Toz Kireç & $\underline{100.14 ~ a ~}$ & $11.14 \mathrm{~b}$ & $\underline{85.73 \mathrm{a}}$ & $75.95 \mathrm{c}$ \\
Granül Kireç & $84.31 \mathrm{c}$ & $11.10 \mathrm{~b}$ & $69.54 \mathrm{c}$ & $78.14 \mathrm{~b}$ \\
Şlam & $97.84 \mathrm{ab}$ & $13.63 \mathrm{a}$ & $75.39 \mathrm{~b}$ & $\underline{79.67 \mathrm{a}}$ \\
\hline \multicolumn{1}{c}{ LSD } & $* *$ & $*$ & $* *$ & $* *$ \\
\hline
\end{tabular}

Aynı harfle gösterilen ortalamalar arasındaki farklılık önemli değildir,

*: $\mathrm{P}<0.05$ düzeyinde önemli farklılık, **: $\mathrm{P}<.01$ düzeyinde önemli farklılık, öd: önemli değil

Biber bitkisi yapraklarında saptanan makro ve mikro besin element miktarları Jones ve ark. (1991) tarafindan verilen yeterlik sınır değerleriyle kıyaslandığında, biber bitkisinin makro ve mikro besin element içeriğinin yeterlilik sınır değerleri içinde yer aldığı dolayısıyla beslenme yönünden herhangi bir sorunun olmadığ anlaşılmıştır (Tablo 9). Hindistan'da şeker fabrikası atıklarının toprağa uygulanması ile topraktaki Fe, $\mathrm{Zn}, \mathrm{Cd}, \mathrm{Cu}$, $\mathrm{Pb}$ and $\mathrm{Cr}$ miktarlarının arttığı rapor edilmiştir (Kumar ve Chopra, 2010). 
Asit reaksiyonlu bir toprağa uygulanan kireçleme materyallerinin $\left(\mathrm{CaCO}_{3}, \mathrm{CaO}, \mathrm{MgCO}_{3}\right.$ ve $\left.\mathrm{MgO}\right)$ mısır bitkisinin verim ve mineral madde içeriğine etkisini belirlemek üzere yapılan bir araştırmada; kireçleme materyallerinin mısır bitkisinin toplam N, P, K, Ca ve Mg konsantrasyonlarını artırdığı saptanmıştır (Kant ve ark., (2006). Aynı araştırıcı bizim bulgularımızdan farklı olarak kireç materyallerinin bitkideki $\mathrm{Fe}, \mathrm{Mn}, \mathrm{Zn}$ ve $\mathrm{Cu}$ alımlarını azalttığını saptamışlardır. Benzer sonuçlar birçok araştırıcı tarafından yapılan çalışmalarla da ortaya konulmuştur (Aydın ve ark., 1997; Turan ve ark., 2002; Şimşek ve Aydın, 2002; Adiloğlu ve ark., 2016)

\section{Tablo 9. Biber bitkisi yapraklarının makro ve mikro besin elementleri için önerilen yeterlik sınır değerleri (Jones ve ark., 1991)}

Table 9. Sufficiency limit values recommended for macro and micro nutrients of pepper plant leaves (Jones ve ark., 1991)

\begin{tabular}{lccc}
\hline Besin Elementi & Yeterlilik Sınır değeri & Besin Elementi & Yeterlilik Sınır değeri \\
\hline Toplam N (\%) & $3.50-5.00$ & Toplam Fe $\left(\mathrm{mg} \mathrm{kg}^{-1}\right)$ & $60-300$ \\
Toplam P (\%) & $0.22-0.70$ & Toplam Cu $\left(\mathrm{mg} \mathrm{kg}^{-1}\right)$ & $6-25$ \\
Toplam K (\%) & $3.50-4.50$ & Toplam Zn $\left(\mathrm{mg} \mathrm{kg}^{-1}\right)$ & $20-200$ \\
Toplam Ca (\%) & $1.30-2.80$ & Toplam Mn $\left(\mathrm{mg} \mathrm{kg}^{-1}\right)$ & $50-250$ \\
Toplam Mg (\%) & $0.30-1.00$ & & \\
\hline
\end{tabular}

\subsection{Granül ve toz kireç ile şlam uygulamalarının biber verimi üzerine etkisi}

Kireçleme materyalleri toz ve granül kireç ile şeker fabrikası atı̆̆ şlamın farklı kombinasyonlarının araştırma materyali biber bitkisinin saksı verimi üzerine etkisi istatistiki anlamda \%1 düzeyinde önemli bulunmuştur. Tüm uygulamalar verimi kontrole oranla artırmıştır. En yüksek biber verimi TK (toz kireç) (276 g.saksi $\left.{ }^{-1}\right)$ ve en düşük verim ise $\mathrm{K}$ (kontrol) uygulamasında (114 g.saksi ${ }^{-1}$ ) elde edilmiştir (Tablo 10).

Tablo 10.Kireç ve şlam uygulamalarının biber verimi üzerine etkisi (g/saksl)

Table 10. The effect of lime and vinasse applications on pepper yield (g/pot)

\begin{tabular}{lc}
\hline Uygulamalar & Verim $(\mathrm{g} / \mathrm{saks1})$ \\
\hline Kontrol & $114 \mathrm{~g}$ \\
1/4 Toz Kireç+3/4 Şlam & $171 \mathrm{~d}$ \\
1/2 Toz Kireç+1/2 Şlam & $190 \mathrm{~d}$ \\
3/4 Toz Kireç+1/4 Şlam & $186 \mathrm{~d}$ \\
1/4 Granül Kireç+3/4 Şlam & $159 \mathrm{e}$ \\
1/2 Granül Kireç+1/2 Şlam & $134 \mathrm{ef}$ \\
3/4 Granül Kireç +1/4 Şlam & $121 \mathrm{ef}$ \\
Toz Kireç & $276 \mathrm{a}$ \\
Granül Kireç & $231 \mathrm{bc}$ \\
Şlam & $249 \mathrm{~b}$ \\
\hline LSD & $* *$
\end{tabular}

Aynı harfle gösterilen ortalamalar arasındaki farklılık önemli değildir, **: $\mathrm{P}<.01$ düzeyinde önemli farkl1lık

Toz kireç uygulamasından sonra biber verimini en fazla artıran uygulamalar ŞL ve GK olmuştur. Bunları izleyen uygulamalardan $1 / 2 \mathrm{TK}+1 / 2$ ŞL, $3 / 4 \mathrm{TK}+1 / 4$ ŞL ve $1 / 4 \mathrm{TK}+3 / 4$ ŞL ise aynı istatistiki grup içerisinde yer almışlardır. Toprak pH'sını yükseltmek amacıyla farklı form, kombinasyon ve miktarlarda uygulanan materyallerin (kireç-şlam) etkisiyle toprak pH'sının yükselmesine bağlı olarak verimde önemli düzeyde artışlar sağladığı saptanmıştır. Kireçlemenin verimi artırdığını bildiren çeşitli araştıııılar, araştırmamızda elde ettiğimiz bulgulara benzer sonuçları farklı bitkiler üzerinde yaptıkları çalışmalarda da saptamışlardır. Farklı bitki çeşitlerinin yetiştirildiği (mısır, soya fasulyesi, buğday, yerfıstığı, yonca, ayçiçeği, çeltik ve kışlık arpa) asit reaksiyonlu topraklara kireç ve kireçli materyal uygulamalarının verimi artırdığı birçok araştırıcı tarafından bildirilmektedir 
Kirece Bir Alternatif Olarak Şlam Uygulamasının Asit Reaksiyonlu Toprakta Biber (Capsicum annuum var. Cerasiforme) Bitkisinin Beslenmesine Etkileri (Busari ve ark., 2008; Kovacevic ve Rastija, 2010; Andric ve ark., 2012; Ngane ve ark., 2012; Rastija ve ark., 2012; Ataur Rahman ve ark., 2013; Karalic ve ark., 2013; Osundwa ve ark., 2013). Araştırmamızda toprak pH'sındaki değişime paralel olarak biber bitkisi veriminde meydana gelen artış sonucu birçok araştırıcının farklı bitkiler ile yaptığı çalışmalardan elde edilen bulgularla benzerlik göstermektedir.

\section{Sonuç ve öneriler}

Farklı form, miktar ve kombinasyonlarda kireçleme materyalleri (granül-toz kireç ile şeker fabrikası atığı şlam) uygulamalarının asit reaksiyonlu bir toprağın $\mathrm{pH}$, mineral madde içeriği ile biber bitkisinin verim ve besin maddesi içeriği üzerine etkisinin araştırıldığı bu çalışmada; toprak pH'sının yükselmesinde en fazla etkili uygulamanın toz kireç olduğu, granül kirecin ise şlam ile aynı etkiyi gösterdiği belirlenmiştir. pH'sı 5.50 olan kontrol toprağın pH'sının TK uygulaması ile 6.42'ye, 1/2 TK+1/2 ŞL uygulaması ile de 6.41'e kadar çıkması sağlanmıştır. Araştırmamızda kireçle birlikte şlam uygulamasının, sadece toz kireç uygulaması ile benzer etkiler göstermesi nedeniyle, asit reaksiyonlu topraklarda $\mathrm{pH}$ düzenlenmesi amacıyla şlam atığının rahatlıkla kullanılabileceği belirlenmiştir. Granül ve toz kireç ile şlam uygulamaları gerek toprağın ve gerekse bitkinin mineral madde içerikleri üzerine de etkili olmuş ve toprakların toplam N, faydalı $\mathrm{P}, \mathrm{Ca}, \mathrm{Fe}$ ve $\mathrm{Zn}$ içerikleri ile bitkinin bazı makro (toplam N, P) ve mikro (Fe, Cu, Zn ve Mn) besin element içeriklerini kontrole oranla önemli oranlarda artırmıştır. Buna bağlı olarak biber verimi de uygulamalardan etkilenmiş ve biber verimini artıran ilk üç uygulama TK $>$ ŞL > GK şeklinde bir sıralama göstermiştir. Sonuç olarak pancar şekeri üretimi esnasında açığa çıkan ve bir çeşit tarımsal atık olan şlamın asit reaksiyonlu topraklarda toprak pH'sını yükseltmek amacıyla alternatif bir kireçleme materyali olarak kullanılabileceğinin saptanması ve tarımsal üretim açısından değerlendirilebilir olması oldukça önemli bir sonuçtur. Bu durum tarımsal atıkların geri kazanımının yanı sıra, tarımsal sürdürülebilirliğe de önemli bir örnek teşkil etme potansiyeli taşımaktadır. Bu atığın değerlendirilmesine katkı sağlayacak benzer çalışmaların, farklı toprak reaksiyonuna sahip topraklarda ve farklı bitki çeşitlerinde üretici koşullarında yapılmasının daha yararlı olacağı düşünülmektedir. 


\section{Kaynakça}

Adiloğlu A., Eryılmaz Açıkgöz F., Adiloğlu S., SolmaZ Y. (2016). Artan Miktarlarda Akuakültür Atığı Uygulamasının Salata (Lactuca sativa L. var. crispa) Bitkisinin Bazı Makro ve Mikro Bitki Besin Elementi İçerikleri Üzerine Etkisi, Tekirdağ Ziraat Fakültesi Dergisi, vol. 13, pp. 96-101.

Aksoy, T., Danışman, S. (1989). Döner çamurunun kireçleme amacıyla kullanılması üzerine bir araştırma. Toprak İlmi Derneği, 10. Bilimsel Toplantı Tebliğleri, s. 43-45.

Altınbaş,Ü, Çengel, M, Uysal, H, Okur, B, Okur, N, Kurucu, Y. Delibacak,S. (2016). Toprak Bilimi. Ege Üniversitesi Ziraat Fakültesi Yayın No. 557, Bornova-İzmir

Andric, L., Rastija, M.,Teklic, T., Kovacevic, V. ( 2012). Response of maize and soybeans to liming. Turk J Agric For 36: 415-420.

Ataur Rahman, M., Barma, N.C.D., Sarker, M.H., Sarker, M.M.R., Nazrul, M.M.I. (2013). Adaptability of wheat varieties in strongly acidic soils of Sylhet. Bangladesh J. Agril. Res., 38(1): 97-104.

Aydın, A., Sezen, Y. ve Özgül, M. (1997). Asit topraklara ilave edilen kirecin toprakların yarayışlı Zn elverişliliğine ve mısır bitkisinin zn alımına etkisi. I. Ulusal Çinko Kongresi 12-16 Mayıs, Eskişehir.

Busari, M.A., Salako, F.K., Adetunji, M.T. (2008). Soil chemical properties and maize yield after application of organic and inorganic amendments to an acidic soil in Soutwestern Nigeria. Spanish Journal of Agricultural Research, 6(4): 691-699.

Castro, G.S.A., Crusciol, C.A.C. (2013). Yield and mineral nutrition of soybean, maize and Congosignalgrass as affected by lime stone and slag. Pesq. Agropec. Bras., 48: 673-681.

Dunn, L.E. (1943). Lime requirement determination of soils by means of titration curves. Soil Sci., 56:341-351.

González-Fernández, P., Espejo-Serrano, R., Ordóñez-Fernández, R., Peregrina-Alonso, F. (2004). Comparative studies of the effeciency of lime refuse from sugar beet factories as an agricultural liming material. Sustainable Organic Waste Management for Environmental Protection and Food Safety,

Jones, J. B. Jr., B. Wolf and H. A. Mills. (1991). Plant analysis handbook. Micro-Macro Publishing, Inc. Georgia 30607, USA.

Kacar, B. ve İnal, A. (2008). Bitki Analizleri. Nobel Yayın No:1241, 892 s.

Kacar, B. (2016). Bitki, Toprak ve Gübre Analizleri 3: Fiziksel ve Kimyasal Toprak Analizleri. Nobel Yayın No: 1524,614 s.

Kant, C., Barik, K., Aydın, A. (2006). Asidik topraklara uygulanan farklı kireçleme materyallerinin bazı toprak özellikleri ile mısır (Zea mays L.) bitkisinin gelişimi ve mineral içeriğine etkisi. Atatürk Üniversitesi Ziraat Fakültesi Dergisi, 37(2): 161-167.

Karabulut, Ö. , Bellitürk, K. (2013). Farklı Magnezyum Kaynaklarının Asit Topraklarda Yetiştirilen Mısır Bitkisinin Potasyum, Kalsiyum ve Magnezyum İçeriğine Etkisi. Tekirdağ Ziraat Fakültesi Dergisi, 10(2): 83-91.

Karalic, K., Loncaric, Z., Popovic, B., Ivezic, V. (2013). Phosphorus and potassium availability change by liming of acid soils. IV. International Symposium, Agrosym 2013, pp. 119-124.

Karaman, M.R., Brohi, A.R., Müftüoğlu, N.M., Öztaş, T., Zengin, M. ( 2012). Sürdürülebilir Toprak Verimliliği.ISBN, 978-605-86684-0-9 genişletilmiş 3. Baskı, Pelin matbaacılık s.167-187.

Kovacevic, V., Rastija, M. (2010). Impacts of liming by dolomite on the maize and barley grain yields. Poljoprivreda, 16(2): 3-8.

Kumar, V., Chopra, A.K. (2010). Influence of sugar mill effluent on physico-chemical characteristics of soil at Haridwar (Uttarakhand), India. Journal of Applied and Natural Science, 2(2):269-279.

Läuchli, A., and Grattan, S. R. (2012). Soil pH extremes, in Plant Stress Physiology, ed. S. Shabala (Wallingford: Centre for Agriculture and Bioscience International), 194. doi: 10.1079/9781845939953.0194.

Msimbira, LA., Smith, DL. (2020). The Roles of Plant Growth Promoting Microbes in Enhancing Plant Tolerance to Acidity and Alkalinity Stresses. Front. Sustain. Food Syst.,4:106. doi.org/10.3389/fsufs.2020.00106

Ngane, E.B., Tening, A.S., Ehabe, E.E., Tchuenteu, F. (2012). Potentials of some cement by-products for liming of an acid soil in the humid zone of South-Western Cameroon. Agriculture and Biology Journal of North America. 3(8): 326-331.

Osundwa, M.A., Okalebo, J.R., Ngetich, W.K., Ochuodho, J.O., Othieno, C.O., Langat, B., Omenyo, V.S. (2013). Influence of agricultural lime on soil properties and wheat (Triticum aestivum L.) yield and acidic soils of Uasin Gishu County, Kenya. American Journal of Experimentel Agriculture, 3(4): 806-823.

Özen, N., Arat, E. (1999). Use of the first carbonification sludge of sugar in dustry as calcium source in quaildiets. Turk. J. Vet. Anim. Sci., 23(1): 35-40.

Özyazıcı, G. (2014). Asit Toprakta Yetişen Fındık (Corylus avellana L.)’ta Kireç ve Şeker Sanayi Atığı Şlamın Verim ve Bazı Toprak Özellikleri Üzerine Etkisi. Türkiye Tarımsal Araştırmalar Dergisi, 1:176-185

Özyazıcı, G., Özdemir, O., Özer, S.P., Kalcıŏlu, Z. (2014). Kireçleme Materyali Olarak Kullanılan Şeker Sanayi Atı̆̆ı Şlamın Çay Bitkisinin Verim, Kalite ve Toprak Özelliklerine Etkisi. Türkiye Tarımsal Araştırmalar Dergisi, 1:43-54. 
Kirece Bir Alternatif Olarak Şlam Uygulamasının Asit Reaksiyonlu Toprakta Biber (Capsicum annuum var. Cerasiforme) Bitkisinin Beslenmesine Etkileri Rastija, D., Semialjac, Z., Rastija, M., Gulisija, A. (2012). Residual effect of liming on soil properties and maize grain yield. Third International Scientific Symposium, Agrosym Jahorina 2012, pp. 87-91.

Sezen, Y. (1981). Asit topraklara kireç ilavesinin fosfor ve potasyum elverişliliğine etkisi. Atatürk Üni. Ziraat Fak,. Ziraat Dergisi, 12(1): 7183.

Şimşek, U. and A. Aydin, (2002). Effects of Lime Application on Some Soil Properties and Mineral Composition and Growth of Corn. International Conference on Sustainable Land Use and Management "Sharing Experiences Sustainable Use of Natural Resources" 10-13 June 2002, Çanakkale-Turkey.

Tevali, İ.E. (2021). Short-term effect of compost amendment on the fertility of calcareous soil and basil growth. Communications In Soil Science and Plant Analysis, 52 (2):172-182.

Turan, M., Sezen, Y. and Aydın, A. (2002). Effect of Different Doses of Lime Material on Soil Properties and Growth of Spinach (spinacia oleracea). International Conference on Sustainable Land Use and Management. Sharing Experiences Sustainable Use of Natural Resources. 10-13 June2002, Çanakkale-Turkey.

Ülgen, N. (1967). Şlam ile kireçleme araştırmaları. Toprak ve Gübre Araştırma Enstitüsü 1962-1963 Yılları Araştırma Raporu, Ankara

Yirga, C., Erkossa, T., and Agegnehu, G. (2019). Soil Acidity Management. Addis Ababa: Ethiopian Institute of Agricultural Research 